Mal J Nutr 27(3): 433-448, 2021

\title{
Prevalence and factors associated with undernutrition among Dayak children in rural areas of Sarawak, Malaysia
}

\author{
Md Mizanur Rahman, Andrew Kiyu \& Neilson Richard Seling \\ Department of Community Medicine and Public Health, Faculty of Medicine and \\ Health Sciences, Universiti Malaysia Sarawak
}

\begin{abstract}
Background: Undernutrition among children has become a major public health issue due to the high risk of morbidity and mortality involving this vulnerable age group. This study focused on the rural population, especially among the Dayak children in Sarawak, Malaysia. Methodology: This community-based cross-sectional study was conducted in Sarawak's rural areas using a multistage stratified cluster sampling technique. Data were collected through face-to-face interviews using an interviewer-guided questionnaire. The nutritional status of the under-five children was measured according to the World Health Organization guidelines. The nutritional indicators were calculated as z-scores. Multivariate logistic regression analyses were performed using SPSS to identify the factors associated with nutritional status. Results: The prevalence of undernutrition among the under-five Dayak children in the rural areas of Sarawak was $39.6 \%$. The analysis suggested that wasting was predominantly associated with parental education levels of primary and below, poor wealth index, environmental and sanitation issues, children with history of low birth weight, shorter duration of exclusive breastfeeding, and poor appetite. Stunting was high within the age group of $<3$ years old and was associated with parents' occupation and household wealth index. Low parental education, poor wealth index, environmental and sanitation issues, poor appetite, and the children's recent illness predicted underweight. Conclusion: These findings imply that a multi-sectoral and multi-dimensional approach is essential to address undernutrition in rural settings. Improvement on households' socioeconomy, environment and sanitation should be emphasised to reduce undernutrition among the children.
\end{abstract}

Keywords: undernutrition, wasting, stunting, underweight, under-five children, Dayak, Sarawak

\section{INTRODUCTION}

Undernutrition among children has always been a major public health issue. The World Health Organization (WHO) reported that globally 170 million children were underweight in 2020 (WHO, 2020a). At the other end of the spectrum, more than 40 million children under the age of five years were overweight, and almost half of the cause of mortality among under-five children was related to malnutrition (Mekonnen et al., 2005). Several indicators have been developed to assess

\footnotetext{
*Corresponding author: Rahman MM

Department of Community Medicine and Public Health, Faculty of Medicine and Health Sciences, Universiti Malaysia Sarawak

Tel: +6082 5811000 ext: 7666; Email: rmmizanur@unimas.my, aniqm@hotmail.com doi: https://doi.org/10.31246/mjn-2021-0045
} 
the nutritional status of children, such as the dietary diversity of individual and household level suggested by the Food and Nutrition Technical Assistance III Project (FANTA, 2006), household food security by Coates, Swindale \& Bilinsky (2007), and level of vitamins and minerals adequacy, and anthropometric measurements (WHO, 2010). In this study, anthropometric measurements were the important indicators that had been used to determine the prevalence of undernutrition in a population of under-five children (Kassa et al., 2017). The WHO defined wasting, stunting, and underweight as $z$-scores $<-2$ standard deviation $(S D)$ for weight-for-height, height-for-age, and weight-for-age, respectively (WHO, 2020b). Worldwide, it was reported that wasting prevalence was $7.3 \%$, stunting $21.3 \%$, and underweight 13.4\% (Dukhi, 2020).

In Malaysia, the prevalence of malnutrition in children has been decreasing over the past decade. The latest report by the National Health and Morbidity Survey (NHMS) 2019 stated that the prevalences of wasting, stunting, and underweight among Malaysian children under five years were 9.4\%, $21.8 \%, 14.1 \%$, respectively (IPH, 2019). In comparison with another local study, Cheah et al. (2012) reported an alarming prevalence of undernutrition among the under-five Orang Asli children in the rural areas of Kelantan with $69.0 \%$ stunting, $40.0 \%$ wasting, and $63.4 \%$ underweight. A few studies had been conducted among the Dayak community children in Sarawak. There was a reportedly high prevalence of stunting and underweight among the under two Penan children in Belaga, Kapit (Bong, Karim \& Ismail, 2018). Eunice, Cheah \& Lee (2014) reported 20.9\% underweight, $10.2 \%$ wasting, and $11.9 \%$ stunting, respectively, among children below five years in a Bidayuh community in Sarawak, Malaysia.
Many factors had been identified as being associated with undernutrition. Parental literacy, family size, duration of breastfeeding, health status, and history of the children's recent illnesses were among the variables associated with undernutrition (Gebre et al., 2019). Sociodemographic and socioeconomic variables also have important influences on childhood malnutrition. Environmental factors such as sources of drinking water, types of sanitation, household built-up materials, and wealth index of households were reported to influence nutritional status (Kassie \& Workie, 2020).

Despite high prevalence of undernutrition, specific studies on the factors affecting the nutritional status of under-five rural Dayak children have not been extensively carried out. The Dayak indigenous communities are among the majority ethnic groups that reside in the rural areas of Sarawak. Because of the remoteness of the Dayak community, differences in sociodemographic and socioeconomic backgrounds could pose some patterns to the children's nutritional status. Thus, this study focused on the prevalence of undernutrition and its determining factors among under-five children in the rural areas of Sarawak, Malaysia.

\section{MATERIALS AND METHODS}

\section{Study setting and population}

This was a cross-sectional communitybased study conducted in Sarawak, Malaysia. Five divisions were randomly selected from 12 administrative divisions in the state. From each selected division, two districts were randomly selected. Then, five villages of Dayak communities were selected from each district. A total of 50 villages were involved in this study. The households in each village were selected through systematic random sampling based on 
the total number of households in the respective village, using the headman's house as the starting point. Sample size was calculated with a base population proportion of children with malnutrition of 43\% (Eunice et al., 2014), with 1.96 standard values for two-tailed tests and $4 \%$ absolute precision. The sample size was further inflated, multiplying by a design effect of 2 and 15\% non-response rate. So, the final sample size was 860. The study respondents consisted of both parents, having at least one under-five child in their households. Respondents who were residents of the study area $<6$ months, seriously ill, had communication difficulties, and had children with special needs and physical deformities that hindered height measurements at the time of data collection, were excluded from the study. In cases where there was $>1$ under-five child in the household, only one child was randomly chosen for data collection.

\section{Data collection instrument}

The instrument had several components based on the objectives of the study. It was prepared in the form of a booklet for easy handling during the interview. The instrument consisted of respondent's sociodemographic characteristics, such as parental age, level of education, type of occupation, size of the family, and household expenditure. Household assets consisted of 22 items that were intended to measure the respondent's economic status. The household environment and sanitation questions had 32 items. These questions were adapted from Lin et al. (2013). Children's characteristics and health status were also included in the questionnaire with 11 items, including their age, gender, upbringing, and medical history. Lastly, the child's body weight $(\mathrm{kg})$ and height (cm) were measured following standard guidelines (WHO, 2008). Children were measured for standing height without shoes using a SECA portable body meter (SECA 206, Germany) to the nearest 0.1 $\mathrm{cm}$. For children 6-23 months of age, recumbent length was measured. Body weight of infants and young children was measured using a digital weighing scale (Tanita 1583, Japan) to the nearest $0.01 \mathrm{~kg}$. Children who were able to stand upright were weighed using a digital lithium-battery weighing scale (Tanita 318 , Japan) to the nearest $0.1 \mathrm{~kg}$. The measurements were recorded in the WHO Anthro version 3.2.2 software, which was downloaded from the WHO website.

\section{Measurement}

\section{Nutritional status}

Height-for-age (HAZ), weight-for-age (WAZ), and weight-for-height (WHZ) $Z$-scores of the children were calculated by WHO Anthro 3.2.2 software according to age and gender. Anthropometric classifications were based on global standards: $\leq 3 S D, \leq 2 S D$, and $\geq 2 S D$. Children with WHZ, HAZ, and WAZ below $-2 S D$ of the reference population's median were considered wasted, stunted, and underweight, respectively (WHO, 2020b).

\section{Wealth quintile}

Wealth index was calculated based on usable household assets by Principal Component Analysis (PCA). Initially, 22 assets were included in the wealth index calculation. The household item with a frequency of $<5 \%$ or $>95 \%$ and communality sources $<0.3$ were excluded from the model. Finally, 18 assets entered a model with KaiserMeyer-Olkin (KMO) and Bartlett's Test that yielded the household's percentage distribution based on quintiles of wealth index. The scores were labelled as poorest for the lowest quintile and the highest quintile as the richest. 
Household characteristics

A proxy economic status of the household was calculated based on in-house facilities and construction materials. The in-house facilities included the source of water supply, lighting, and type of sanitation. The construction materials were pertaining to the material composition of the walls, floor, ceiling, and roofing of the house described by Yakubu, Akaateba \& Akanbang (2014). Based on the majority frequency of usage, the items were further classified into items, i.e., 'yes' for having the proper items and 'no' for improper items in the house. It yielded a total of seven items. Therefore, out of seven items, the score of 4 or less was considered Poor, 5-Satisfactory, 6-Good, and 7 - Excellent (Morris et al., 2000).

\section{Data collection procedure}

A pilot test was conducted among 30 respondents. The purpose of this test was to determine whether the wordings used were clear and whether there was a need to further refine the questionnaire. Domain-wise, Cronbach's alpha was calculated, and it varied from 0.688 to 0.890 . The interviewers were trained for one week to ensure high quality data were collected. Prior to data collection, a briefing session was held by the researcher and his team. This session was made compulsory to clearly understand the study objectives, selection criteria of the respondents, sampling methods, and proper manner for conducting interview to ensure everyone was tailored to their roles in data collection. The questionnaires were checked to make sure that relevant questions had been responded to and coded accordingly. The questionnaire distribution and collection was done between April 2019 till February 2020. At the end of the study period, a total of 920 questionnaires were distributed according to the divisions, districts and villages, and 808 complete responses were received, yielding a response rate of $88.2 \%$. Data were collected by faceto-face interviews at a comfortable time. Three attempts were made to get the sampled respondents.

\section{Ethical issues}

Participation in this study was entirely voluntary. Respondents were briefed about the confidentiality of the information given. Informed written consent was obtained from the participants. No financial or any other incentives were provided for their participation. The study received ethical approval from the Ethics Committee of the Faculty of Medicine and Health Science, Universiti Malaysia Sarawak (UNIMAS) [UNIMAS/NC-21.02/03-02 Jld.3 (80)] and the Medical Research and Ethics Committee (MREC), Ministry of Health Malaysia [KKM/NIHSEC/P19877 (6)].

\section{Data analysis}

Any missing information in the questionnaire was corrected on the same day or the next day. Data coding and verification of response was made on the same day immediately after the interview. Complete data were entered into Microsoft Office Excel 2010 with a validation check. From Microsoft Excel, the data were exported to IBM Statistical Package for Social Science (SPSS) version 22.0. They were then validated for any inconsistencies, missing values, and duplication. The analysis output was presented in the form of mean, median, minimum and maximum values, and standard deviation for continuous data, and percentages for categorical data. All continuous variables were then transformed into categorical data for further analysis. Binomial logistic regression analysis was used to predict 
the factors that affected the nutritional status of under-five children. Before interpreting the results, Chi-square goodness of fit, Nagelkerke $R^{2}$, predictive accuracy and classification were checked for model fit adequacy. A $p$-value of $\leq 0.05$ was considered statistically significant.

\section{RESULTS}

\section{Sociodemographic and} socioeconomic of the respondents

A total of 808 household data were analysed in this study. Almost half of the fathers $(45.6 \%)$ were 25 to 34 years old, followed by the age group of 35 to 44 years (35.4\%). The mean age for fathers was 35.37 (8.28) years old. The mean age for mothers was $32.42(7.63)$ years old, with the majority (56.9\%) from the age group of 25 to 34 years old. Nearly four-fifths $(78.3 \%)$ of the fathers had secondary level and above of education, while $73.0 \%$ of the mothers attained secondary level and above of education. One-third $(35.5 \%)$ of the fathers were unemployed, followed by self-employed $(32.9 \%)$, and working in private sectors (21.2\%). The unemployment rate among the mothers was $69.7 \%$, with only $30.3 \%$ being employed either as self-employed or working in private or government sectors. The median family size was six persons, with a minimum of two persons and a maximum of 15 persons in the household. The percentage distribution of the wealth quintile of the households was almost equal among the five groups, with a little extra percentage among the richest quintile $(22.3 \%)$ or 180 households. The good score for household characteristics was the highest among the four categories at $30.7 \%$ or 248 households, followed by the poor score at $27.3 \%$ (221 households), excellent score at $17.6 \%$ (142 households), and $24.4 \%$ or 197 households with a satisfactory score (Table 1).

\section{Characteristics of children and their health status}

Among the under-five children, slightly more than half were boys $(51.1 \%)$. The children's mean age was 30.35 months, with a minimum age of six months and a maximum age of 59 months. About one-fifth $(22.2 \%)$ of children were born low birth weight $(<2.5 \mathrm{~kg})$. More than half were in the second to fourth birth order among their siblings. Seven-tenths $(71.0 \%)$ of the children were exclusively breastfed six months or less, while $29.0 \%$ were breastfed for $>6$ months. A high percentage of children had a good appetite in the past week (78.5\%). Although majority of the children had no illness in the past 14 days, $12.5 \%$ or 101 children had a fever, 40 children $(5.0 \%)$ had respiratory illness, and $27(3.3 \%)$ children had experienced gastrointestinal illness (Table 2).

\section{Nutritional status of the children}

Weight-for-height indicated that 1.2\% were severely wasted, while $5.7 \%$ were wasted. Normal weight-for-height was $87.8 \%$, and $5.3 \%$ were having a risk of being overweight. As for the heightfor-age indicator for stunting, $2.8 \%$ were severely stunted, $16.1 \%$ were stunted, while $81.1 \%$ were within the normal category. Weight-for-age nutritional status showed that $14.2 \%$ were underweight, $0.4 \%$ were severely underweight, while $85.4 \%$ had normal weight-for-age (Table 3).

\section{Patterns of undernutrition problems}

Table 4 illustrates the patterns of standalone and co-occurrence of nutritional problems in children. It was found that the highest percentage of children with standalone forms of malnutrition were stunted (9.4\%), followed by $2.8 \%$ being wasted, and $2.4 \%$ underweight. However, the total percentage of co-occurrence of 
Table 1. Characteristics of the respondents and households

\begin{tabular}{|c|c|c|c|}
\hline Characteristics & $n$ & $\%$ & Statistics \\
\hline \multicolumn{4}{|l|}{ Father's age in years } \\
\hline$<25$ & 53 & 6.6 & \\
\hline $25-34$ & 367 & 45.4 & Mean $\pm S D=35.37 \pm 8.28$ \\
\hline $35-44$ & 286 & 35.4 & $\operatorname{Min}=21, \operatorname{Max}=63$ \\
\hline$\geq 45$ & 102 & 12.6 & \\
\hline \multicolumn{4}{|l|}{ Mother's age in years } \\
\hline$<25$ & 85 & 10.6 & \\
\hline $25-34$ & 460 & 56.9 & Mean $\pm S D=32.42 \pm 7.63$ \\
\hline $35-44$ & 199 & 24.6 & $\operatorname{Min}=20, \operatorname{Max}=60$ \\
\hline$\geq 45$ & 64 & 7.9 & \\
\hline \multicolumn{4}{|l|}{ Father's level of education } \\
\hline Primary and below & 175 & 21.7 & \\
\hline Secondary and above & 633 & 78.3 & \\
\hline \multicolumn{4}{|l|}{ Mother's level of education } \\
\hline Primary and below & 217 & 26.9 & \\
\hline Secondary and above & 591 & 73.1 & \\
\hline \multicolumn{4}{|l|}{ Occupation of father } \\
\hline Unemployed & 287 & 35.5 & \\
\hline Government jobs & 84 & 10.4 & \\
\hline Private jobs & 171 & 21.2 & \\
\hline Self-employed & 266 & 32.9 & \\
\hline \multicolumn{4}{|l|}{ Occupation of mother } \\
\hline Unemployed & 563 & 69.7 & \\
\hline Government jobs & 77 & 9.5 & \\
\hline Private jobs & 71 & 8.8 & \\
\hline Self-employed & 97 & 12.0 & \\
\hline \multicolumn{4}{|l|}{ Family size } \\
\hline $2-3$ & 75 & 9.4 & \\
\hline $4-5$ & 284 & 35.1 & Mean $\pm S D=6.1 \pm 2.1$ \\
\hline $6-7$ & 263 & 32.5 & Median $=6$ \\
\hline $8-9$ & 107 & 13.2 & Min, $\operatorname{Max}=2,15$ \\
\hline$\geq 10$ & 79 & 9.8 & \\
\hline \multicolumn{4}{|l|}{ Wealth quintile } \\
\hline Poorest & 161 & 19.9 & \\
\hline Poor & 151 & 18.6 & \\
\hline Middle & 158 & 19.6 & \\
\hline Rich & 158 & 19.6 & \\
\hline Richest & 180 & 22.3 & \\
\hline \multicolumn{4}{|l|}{ Household characteristics } \\
\hline Poor $(\leq 4)$ & 221 & 27.3 & \\
\hline Satisfactory (5) & 197 & 24.4 & \\
\hline Good (6) & 248 & 30.7 & \\
\hline Excellent (7) & 142 & 17.6 & \\
\hline
\end{tabular}


Table 2. Characteristics of the children

\begin{tabular}{|c|c|c|c|}
\hline Characteristics & $n$ & $\%$ & Statistics \\
\hline \multicolumn{4}{|l|}{ Age (months) } \\
\hline$<11$ & 107 & 13.2 & \\
\hline $11-23$ & 204 & 25.3 & Mean $\pm S D=30.35 \pm 16.16$ \\
\hline $24-35$ & 169 & 20.9 & Median $=29$ \\
\hline $36-47$ & 144 & 17.8 & $\operatorname{Min}=6 ; \operatorname{Max}=59$ \\
\hline $48-59$ & 184 & 22.8 & \\
\hline \multicolumn{4}{|l|}{ Gender } \\
\hline Male & 413 & 51.1 & \\
\hline Female & 395 & 48.9 & \\
\hline \multicolumn{4}{|l|}{ Birth weight (kg) } \\
\hline$\geq 2.5$ & 629 & 77.8 & \\
\hline$<2.5$ & 179 & 22.2 & \\
\hline \multicolumn{4}{|l|}{ Birth order } \\
\hline First & 297 & 36.8 & Mean $\pm S D=2.23 \pm 1.33$ \\
\hline $2^{\text {nd }}$ to $4^{\text {th }}$ & 455 & 56.3 & Median $=2, \operatorname{Min}=1 ; \operatorname{Max}=9$ \\
\hline $5^{\text {th }}$ or higher & 56 & 6.9 & \\
\hline \multicolumn{4}{|c|}{$\begin{array}{l}\text { Duration of exclusive } \\
\text { breastfeeding (months) }\end{array}$} \\
\hline$\leq 6$ months & 574 & 71.0 & Mean $\pm S D=3.97 \pm 1.69$ \\
\hline$>6$ months & 234 & 29.0 & Median $=4, \operatorname{Min}=1 ; \operatorname{Max}=8$ \\
\hline \multicolumn{4}{|c|}{$\begin{array}{l}\text { Parents' perception } \\
\text { on child's eating appetite }\end{array}$} \\
\hline Good & 634 & 78.5 & \\
\hline Moderate & 148 & 18.3 & \\
\hline Poor & 26 & 3.2 & \\
\hline \multicolumn{4}{|c|}{ Types of illness in the past 14 days } \\
\hline No illness & 640 & 79.2 & \\
\hline Fever & 101 & 12.5 & \\
\hline Respiratory & 40 & 5.0 & \\
\hline Gastrointestinal & 27 & 3.3 & \\
\hline
\end{tabular}

undernutrition problems involving stunting was $18.1 \%$, followed by underweight $14.2 \%$, and wasting (6.6\%).

\section{Factors associated with}

\section{undernutrition: Multivariate analysis}

Parental age, family size, and children's gender were factors excluded in the multivariate analysis as these variables were not statistically significant in the Chi-square test of independence.

\section{Wasting}

The multivariate analysis showed that fathers with education level of primary and below $(\mathrm{AOR}=1.139,95 \% \mathrm{CI}: 0.448-$ 2.405), mothers with education level of primary and below (AOR $=7.489$, 95\% CI: 3.275-17.122), poorest wealth index (Quintile 1) (AOR=4.835, 95\% CI: 1.251-18.681), poor environment and sanitation score $(\mathrm{AOR}=2.603$, 95\% CI: 0.973-5.361), birth weight of $<2.5 \mathrm{~kg}(\mathrm{AOR}=2.106,95 \% \mathrm{CI}: 1.084-$ 4.090), and poor eating appetite in the past one week $(\mathrm{AOR}=2.376,95 \% \mathrm{CI}$ : 0.108-1.306) were independent positive predictors for wasting among the children, while the duration of exclusive breastfeeding of six months and above 
(AOR=0.397, 95\% CI: 0.202-0.780) was the only negative predictor for wasting among the children (Table 5). Children whose fathers had an education level of primary and below were 1.139 times more likely to be wasted, and mothers with similar education levels were 7.489 times more likely to be wasted than fathers and mothers with an education level of secondary and above. The poorest wealth index households increased the likelihood of children being wasted at 4.835 times compared to the richest wealth index households. Children with poor environment and sanitation were 2.603 times more likely to be wasted than those with excellent environment and sanitation, while children with a history of low birth weight were 2.106 times more likely to be wasted compared to those with a birth weight of $>2.5 \mathrm{~kg}$. Children who experienced a duration of exclusive breastfeeding for $>6$ months had 0.397 times of prevalence in wasting than those breastfed six months and less. Children with poor eating appetite were 2.376 times likelier to be wasted compared to those with good eating appetite.

\section{Stunting}

The independent predictors for stunting among the children were the unemployment status of fathers (AOR=1.726, 95\% CI: 1.014-2.938) and mothers (AOR $=2.888,95 \%$ CI: 1.3016.412), and each of the household wealth indices, from the poorest (AOR=5.895, 95\% CI: 2.377-14.623), poor $\quad(A O R=5.221, \quad 95 \% \quad C I: \quad 2.199-$ 12.400), middle (AOR=3.477, 95\% CI: $1.506-8.029)$ to rich $(\mathrm{AOR}=3.243$, 95\% CI: 1.405-7.484) households. Children whose fathers and mothers were unemployed were 1.726 times and 2.888 times more likely to be stunted, respectively. Based on wealth index, children with poor household scores were more likely to be stunted compared to those with richer household scores. Apart from that, the age of the children had a significant association as well,

Table 3. Nutritional status of the children

\begin{tabular}{lcc}
\hline Nutritional status & $n$ & $\%$ \\
\hline${ }^{\dagger}$ Weight-for-height (wasted) & & \\
Severely wasted & 10 & 1.2 \\
Wasted & 46 & 5.7 \\
Normal & 709 & 87.8 \\
Risk of overweight & 43 & 5.3 \\
${ }^{\ddagger}$ Height-for-age (stunted) & & \\
Severely stunted & 23 & 2.8 \\
Stunted & 130 & 16.1 \\
Normal & 655 & 81.1 \\
sWeight-for-age (underweight) & & \\
Severely underweight & 3 & 0.4 \\
Underweight & 115 & 14.2 \\
Normal & 690 & 85.4 \\
\hline
\end{tabular}

${ }^{\dagger}$ Weight-for-height: severely wasted $(\leq-3 S D)$, wasted $(\leq-2 S D)$, normal $(>-2 S D$ to $<2 S D)$, overweight $(\geq 2 S D)$ and obese $(\geq 3 S D)$

${ }^{\ddagger}$ Height-for-age: severely stunted $(\leq-3 S D)$, stunted $(\leq-2 S D)$ and normal $(>-2 S D$ to $<2 S D)$

§Weight-for-age: severely underweight $(\leq-3 S D)$, underweight $(\leq-2 S D)$ and normal $(>-2 S D$ to $<2 S D)$ 
notably the age groups of 36 months to 47 months (AOR $=0.469$, 95\% CI: 0.2631.336) and 48 months to 59 months (AOR=0.592，95\% CI: 0.324-1.079). Children in these two age groups were 0.469 times and 0.592 times more likely to be stunted, respectively, compared to children $<11$ months old (Table 5).

\section{Underweight}

The multivariate analysis showed that the independent variables that were associated with the prevalence of underweight were: fathers $(\mathrm{AOR}=1.453$, 95\% CI: 0.510-2.977) and mothers $(\mathrm{AOR}=3.192, \quad 95 \% \quad \mathrm{CI}: \quad 1.646-6.191)$ with education level of primary and below; wealth index of households, from the poorest $(\mathrm{AOR}=3.634,95 \% \mathrm{CI}$ : $1.362-9.694)$, poor $(\mathrm{AOR}=2.565,95 \%$ CI: 1.001-6.574) to rich (AOR=1.405, 95\% CI: 0.894-3.246), and having poor environment and sanitation within the household (AOR=1.429, 95\% CI: 0.8402.432). Poor eating appetite in the past one week $(\mathrm{AOR}=2.213,95 \% \mathrm{CI}$ : 1.7874.334) and fever as an illness in the past 14 days $(\mathrm{AOR}=2.537,95 \% \mathrm{CI}: 1.158$ 5.368) were also important variables that influenced underweight status among the children (Table 5). In comparison, fathers and mothers with an education level of primary school and below were 1.453 times and 3.192 times more likely to have children who were underweight than parents with an education level of secondary school and above.

In general, children who lived in poor households were more likely to be underweight compared to rich households. Children with poor environmental and sanitation scores were 1.429 times more likely to be underweight than children from households with excellent scores. Besides that, children with poor eating appetite were 2.213 times more likely to be underweight than those with a good eating appetite. Children with a history of fever were 2.537 times more likely to be underweight too compared to children with no history of illness.

\section{DISCUSSION}

Child malnutrition continues to be a major public health problem in developing countries, including Malaysia. Children are the most vulnerable to be malnourished due to multiple factors (Rikimaru et al., 1998). The socioeconomic status of a household is one of the contributing factors. Socioeconomic status is also associated with occupation, which is indirectly related to the level of education in the household. In this study, several factors were found to influence undernutrition

Table 4. Distribution patterns of undernutrition problems among children

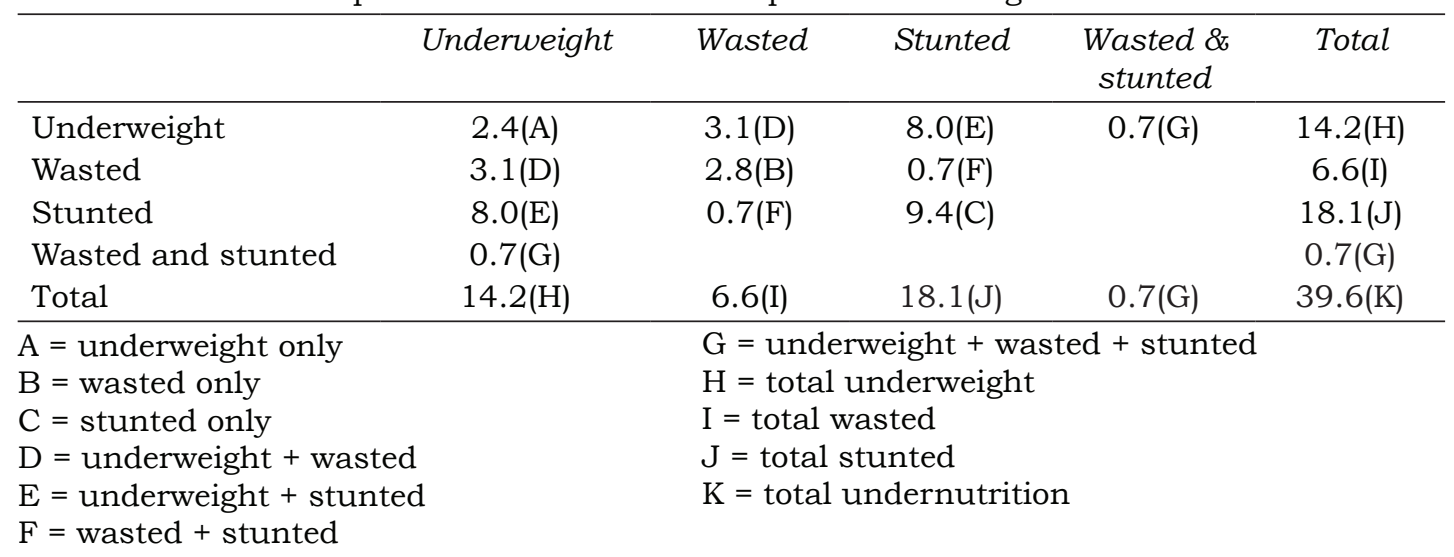




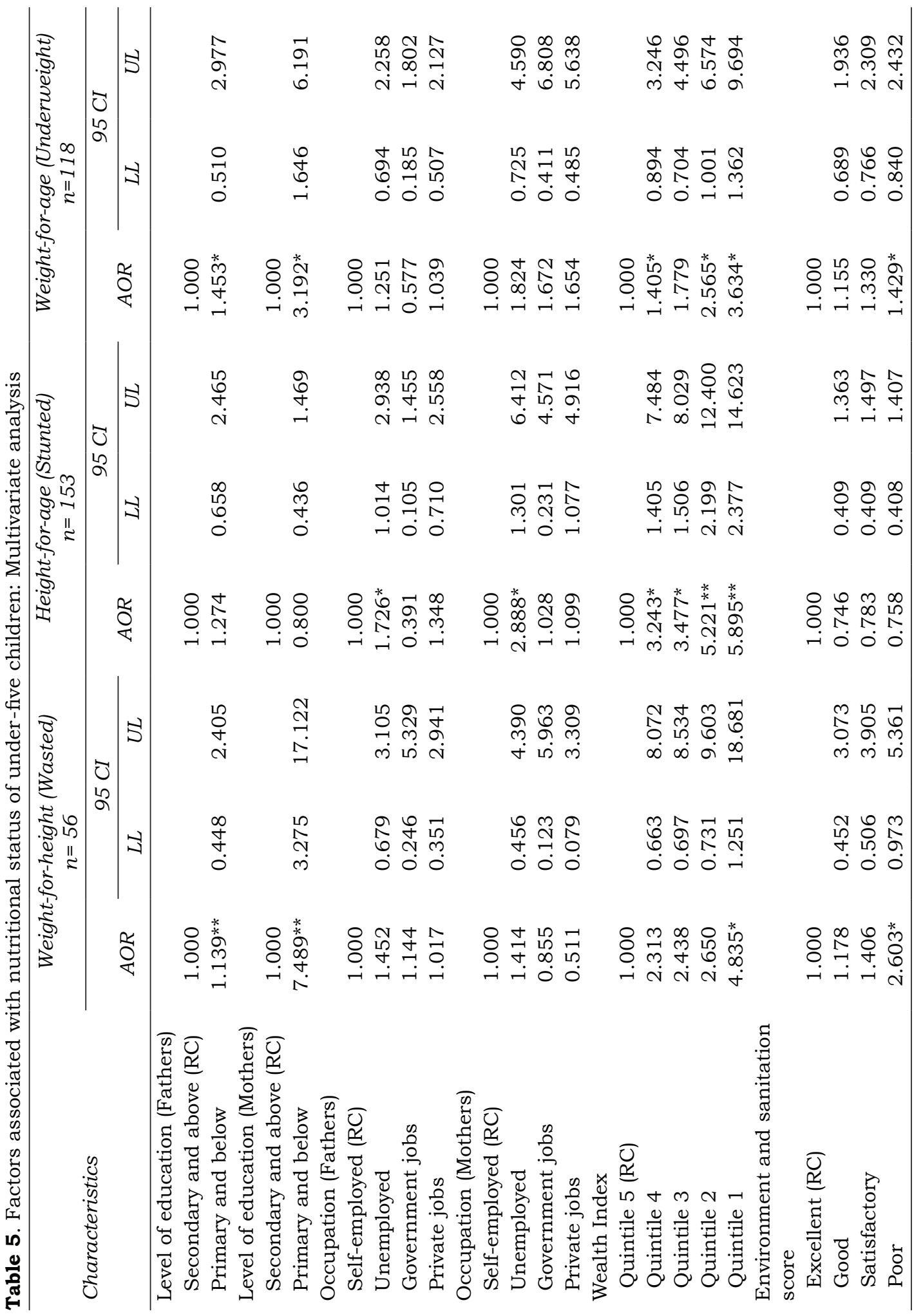


Undernutrition among Dayak children in Sarawak, Malaysia

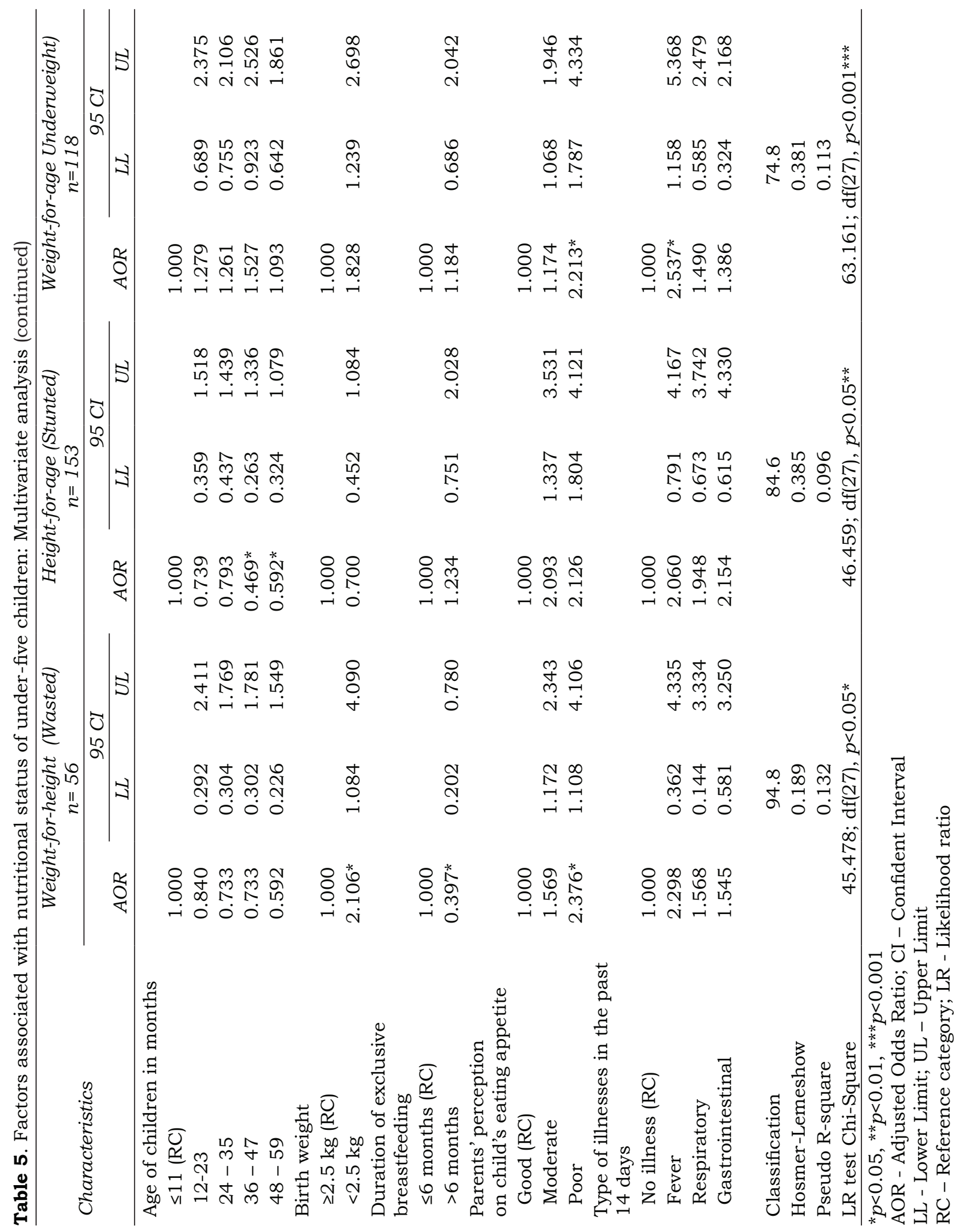


among Dayak children in the rural areas of Sarawak, Malaysia. The prevalence of undernutrition, which comprised of wasting, stunting, and underweight, were assessed to determine the extent of this public health issue among the children in rural areas. The current study revealed that $5.7 \%, 16.1 \%$, and $14.2 \%$ of the under-five children were wasted, stunted, and underweight, respectively. However, these observed prevalences were lower than the UNICEF/WHO/ The World Bank Group joint child malnutrition estimates in 2021 (WHO, 2021).

In comparison with the other upper middle-income countries such as Thailand, it was reported that the prevalences of wasting, stunting, and underweight among the under-five children in rural areas were $4.8 \%$, $17.4 \%$, and $11.0 \%$, respectively (UNICEF, 2018). NHMS 2019 reported that the prevalences of wasting, stunting, and underweight among Malaysian children under five years in the rural areas were $8.5 \%, 22.2 \%$, and $15.6 \%$, respectively, with wasting and stunting noted to be significantly higher compared to the current study. However, this is taking into consideration the high prevalence of undernutrition contributed by the Orang Asli children in rural areas of Peninsular Malaysia, as reported by Cheah et al. (2012), and the rural districts of Sabah by How et al. (2020). On the other hand, the prevalence of underweight in the current study was slightly higher compared to the national prevalence of underweight. This could be the small margin of difference between children who lived in rural and urban settings, whereby urban children have more issues of overweight and obesity than underweight (Agbozo et al., 2016).

The pattern of nutritional status with stunting predominating over wasting indicated long nutritional deficiency among the under-five children, with underweight that signified acute and chronic nutritional deficiency. Chronic malnutrition is common among rural children as compared to urban children. However, not many studies have pointed to the co-occurrence of malnutrition; thus, the current study revealed the seriousness of nutritional deficiency periods experienced by the rural children that needs urgent medical interventions to treat those that are affected.

Among the factors that influenced wasting were the parents' level of education, poor household wealth index, environmental and sanitation factor, birth weight of $<2.5 \mathrm{~kg}$, shorter breastfeeding period, and poor eating appetite among the children. The household's socioeconomic status that were related to children's growth included parents' education, wealth index, and environmental and sanitation factors. These findings are consistent with Amare, Ahmed \& Mehari (2019), where poor socioeconomic background was strongly related to malnourished children. Perceived child size at birth significantly determined the nutritional status of a child. Low birth weight can lead to a high risk of undernutrition in children (Rahman et al., 2016). The current study showed that prolonged breastfeeding of $>6$ months reduced the risk of wasting among the children. The parent's perception of their children's poor appetite also reflected wasting among the children, whereby children experienced weight loss due to acute malnutrition (Gebre et al., 2019). Poor eating appetite was almost similar to the loss of eating appetite, where the parents perceived that their children were unable to finish their usual portion of foods per meal (Scaglioni et al., 2018). Apart from the parent's status of being unemployed, the prevalence of undernutrition was also associated with household wealth index, as well as environmental and sanitation factors. 
Several studies indicated that a poorer wealth index was associated with a higher risk of undernutrition in children due to the lower priority for intrahousehold investment and resourceconstrained households (Wali, Agho \& Renzaho, 2020). The wealth index factor also influenced the adequacy of nutrition and proper living conditions (Wali et al., 2020).

The risk of stunting was reduced when the children were in the age group of three years to five years old, in comparison with children in the age group of $<3$ years old. It is quite common for stunting to start increasing before the age of three years. This is because stunting is a sign of chronic undernutrition, and therefore, takes time to manifest compared with other undernutrition indicators. However, this finding varies in different countries. The prevalence of stunting was the highest among the age group of $<2$ years old in India, but a lower prevalence was reported in Maldives (Wali et al., 2020). Jiang et al. (2015) reported a similar finding among the children in midwestern rural areas of China. This is probably because children $>3$ years old would have already established their feeding pattern, whereas children $<3$ years old were still at their transition feeding period.

Subsequent analysis showed that parental education and occupation affected the prevalence of underweight in children. Low levels of parental education had increased the risk of children with underweight. These findings were consistent with Hossain and Khan in Bangladesh (Hossain \& Khan, 2018), where the higher the parental education, the lesser the risk of malnutrition. Better education ensured job security and better occupation and thus, improved the socioeconomic of the household. The wealth index in this study also proved that it had affected the nutritional status of the children. Low wealth index was associated with a higher risk of being underweight, while moderate to the wealthiest had reduced malnutrition risk in the households (Kassie \& Workie, 2020).

Environmental and sanitation were seen as important variables that influenced undernutrition among the children. Poor sanitation and household environment led to an increased risk of 1.5 times in underweight compared to excellent sanitation and environment. Better sanitation and environment leads to reduced risk of diarrhoea-associated infections, including intestinal worms that can result in insufficient nutrient intakes and undernutrition among the vulnerable groups, particularly the under-five children. Improvement of water supply and cooked foods in the households have also been reported to reduce the risk of food-borne disease among the children and thus, lower the risk of undernutrition (Muoki et al., 2008; Mshida et al., 2018).

In our study, parents' perception of poor appetite among their children also revealed an increased risk of underweight by 2.2 times compared to children with good eating appetite. Eating appetite is responsive to external stimuli associated with the presence of food, smell or taste (Freitas et al., 2018). Good eating appetite was also influenced by eating behaviour, food availability prepared in the households, parental factors, and family environment support (Scaglioni et al., 2018). A recent fever resulted in the increased risk of underweight by 2.5 times compared to children without such history. It was also noted that poor eating appetite reduced the nutrient adequacy of children during such illness. Similar findings had been reported previously (Kassie \& Workie, 2020).

In this research, both husband and wife were the respondents in each household to improve the recall of 
history. Other important factors that might be associated with nutritional status need to be included in the study, such as maternal characteristics like body mass index and history of any antenatal risk factors. Apart from that, parents might not have given accurate information about their children's birth history and health status compared to the mothers in the households. Therefore, it is recommended that researchers assess medical history records and antenatal documents to verify their findings in future research.

\section{CONCLUSION}

The prevalence of undernutrition among the under-five Dayak children in the rural areas of Sarawak was low compared to the national and WHO levels. Wasting was predominantly associated with low parental education levels, poor wealth index, environmental and sanitation issues, low birth weight, shorter duration of exclusive breastfeeding, and perception of poor eating appetite among the children. Apart from parental occupation, the prevalence of stunting was associated with household wealth index and within the age group of $<3$ years old. The prevalence of underweight was influenced by low parental education levels, poor environment and sanitation, perception of poor eating appetite, and recent illness in children. These findings would contribute to the effort of tackling childhood undernutrition as a high priority public health issue. Government and non-government organisations should focus on prevention and an integrated approach to assist the rural poor, especially by creating more job opportunities in the rural areas, which may subsequently improve household wealth, environment, and sanitation. Awareness through health education among mothers pertaining to the importance of exclusive breastfeeding and child nutrition needs to be emphasised by health educators with support from the surrounding community.

\section{Acknowledgements}

We are very grateful to the Ketua Kampung (village headmen) for their support in selecting the houses and identification of respondents through the development of a sampling frame. We are also grateful to the research assistants who were involved in data collection. Furthermore, our gratitude goes to all the respondents who participated in this study. We received a small grant from Yayasan Dayak Chair (Ref: F05/ DRC/1810/2019), Institute of Borneo Studies, Universiti Malaysia Sarawak. We are grateful to Universiti Malaysia Sarawak for supporting this research.

\section{Authors' contributions}

RMM, principal investigator, conceptualised and designed the study, analysed the data, prepared the draft of the manuscript and reviewed the manuscript; KA, conceptualised and designed the study, and reviewed the manuscript; SNR, led the data collection, advised on data entry, analysis and interpretation, and reviewed the manuscript.

\section{Conflict of interest}

The authors declare no potential conflicts of interest concerning the research, authorship, and publication of this article.

\section{References}

Agbozo F, Atito P \& Abubakari A (2016). Malnutrition and associated factors in children: A comparative study between public and private schools in Hohoe Municipality, Ghana. BMC Nutr 2(1):32. https://doi.org/10.1186/ s40795-016-0073-7

Amare ZY, Ahmed ME \& Mehari AB (2019). Determinants of nutritional status among children under age 5 in Ethiopia: Further analysis of the 2016 Ethiopia demographic and health survey. Global Health 15(1):62. https:// doi.org/10.1186/s12992-019-0505-7

Bong M, Karim NA \& Ismail MN (2018). Nutritional status and complementary feeding among Penan infants and young children in rural Sarawak, Malaysia. Mal J Nutr 24(4):539-550.

Cheah WL, Wan Muda WAM, Mohd Hussin ZA \& Chang CT (2012). Factors Associated With Undernutrition Among Children in a Rural District of Kelantan, Malaysia. Asia Pac $J$ Public Health 24(2):330-342. https://doi. org/10.1177/1010539510380737 
Coates J, Swindale A \& Bilinsky P (2007). Household Food Insecurity Access Scale (HFIAS) for Measurement of Food Access: Indicator Guide: Version 3: (576842013-001) [Data set]. American Psychological Association. https:// doi.org/10.1037/e576842013-001

Dukhi N (2020). Global Prevalence of Malnutrition: Evidence from Literature. In M Imran \& A Imran (Eds.), Malnutrition (pp. 1-16). Intechopen. https://doi.org/ 10.5772/intechopen.92006

Eunice MJ, Cheah WL \& Lee PY (2014). Factors influencing malnutrition among young children in a rural community of Sarawak. Mal $J$ Nutr 20(2):145-164. https://ir.unimas.my/ id/eprint/5204/

FANTA (2006). Household Dietary Diversity Score (HDDS) for Measurement of Household Food Access: Indicator Guide | Food and Nutrition Technical Assistance III Project (FANTA). Food and Nutrition Technical Assistance III Project (FANTA). https://www.fantaproject. org/monitoring-and-evaluation/householddietary-diversity-score

Freitas A, Albuquerque G, Silva C \& Oliveira A (2018). Appetite-related eating behaviours: An overview of assessment methods, determinants and effects on children's weight. Ann Nutr Metab 73(1):19-29. https://doi. org/10.1159/000489824

Gebre A, Reddy PS, Mulugeta A, Sedik Y \& Kahssay M (2019). Prevalence of malnutrition and associated factors among under-five children in pastoral communities of Afar Regional State, Northeast Ethiopia: A communitybased cross-sectional study. J Nutr Metab 2019:9187609. doi: 10.1155/2019/9187609. PMID: 31275645 ; PMCID: PMC6589243.

Hossain MB \& Khan MHR (2018). Role of parental education in reduction of prevalence of childhood undernutrition in Bangladesh. Public Health Nutr 21(10):1845-1854. https:/ / doi.org/10.1017/S1368980018000162

How ETC, Shahar S, Robinson F, Manah AM, Ibrahim MY, Jeffree MS, Rahim SSSA \& Yusuff AS (2020). Risk factors for undernutrition in children under five years of age in Tenom, Sabah, Malaysia. Malaysian J Public Health Med 20(1):71-81. https://doi.org/10.37268/ mjphm/vol.20/no.1/art.557
IPH (2019). National Health and Morbidity Survey (NHMS) 2019: Vol. I: NCDs - NonCommunicable Diseases: Risk Factors and other Health Problems. Institute for Public Health, National Institutes of Health, Ministry of Health Malaysia. From: https://iku.moh. gov.my / images / IKU / Document / REPORT / NHMS2019/Report_NHMS2019-NCD_v2.pdf. [Retrieved November 5 2021]

Jiang Y, Su X, Wang C, Zhang L, Zhang X, Wang L $\&$ Cui Y (2015). Prevalence and risk factors for stunting and severe stunting among children under three years old in mid-western rural areas of China. Child Care Health Dev 41(1):4551. https://doi.org/10.1111/cch.12148

Kassa ZY, Behailu T, Mekonnen A, Teshome M \& Yeshitila S (2017). Malnutrition and associated factors among under five children (6-59 Months) at Shashemene Referral Hospital, West Arsi Zone, Oromia, Ethiopia. Curr Pediatr Res 21(1):172-180.

Kassie GW \& Workie DL (2020). Determinants of under-nutrition among children under five years of age in Ethiopia. BMC Public Health 20(1):399. https://doi.org/10.1186/s12889020-08539-2

Lin A, Arnold BF, Afreen S, Goto R, Huda TMN, Haque $\mathrm{R}$, Raqib $\mathrm{R}$, Unicomb $\mathrm{L}$, Ahmed $\mathrm{T}$, Colford JM \& Luby SP (2013). Household Environmental Conditions Are Associated with Enteropathy and Impaired Growth in Rural Bangladesh. Am J Trop Med Hyg 89(1):130137. https://doi.org/10.4269/ajtmh.12-0629

Mekonnen A, Jones NA \& Tefera B (2005). Tackling child malnutrition in Ethiopia: Do the Sustainable Development Poverty Programme's underlying policy assumptions reflect local realities? Young Lives, Save the Children UK.

Mshida HA, Kassim N, Mpolya E \& Kimanya M (2018). Water, Sanitation, and Hygiene Practices Associated with Nutritional Status of Under-Five Children in Semi-Pastoral Communities Tanzania. Am J Trop Med Hyg 98(5):1242-1249. https://doi.org/10.4269/ ajtmh.17-0399

Morris SS, Carletto C, Hoddinott J \& Christiaensen LJM (2000). Validity of rapid estimates of household wealth and income for health surveys in rural Africa. $J$ Epidemiology Community Health 54(5):381-387. https: / / doi. org/10.1136/jech.54.5.381 
Muoki M, Tumuti D \& Rombo D. (2008). Nutrition and public hygiene among children under five years of age in Mukuru slums of Makadara division, Nairobi. East Afr Med J 85(8):386-397. https://doi.org/10.4314/eamj.v85i8.9656

Rahman MS, Howlader T, Masud MS \& Rahman ML (2016). Association of low-birth weight with malnutrition in children under five years in Bangladesh: Do mother's education, socioeconomic status, and birth interval matter? PLOS ONE 11(6):e0157814. https://doi. org/10.1371/journal.pone.0157814

Rikimaru T, Yartey JE, Taniguchi K, Kennedy DO \& Nkrumah FK (1998). Risk factors for the prevalence of malnutrition among urban children in Ghana. $J$ Nutr Sci Vitaminol 44(3):391-407. jnsv. 44.391

Scaglioni S, De Cosmi V, Ciappolino V, Parazzini F, Brambilla P \& Agostoni C (2018). Factors influencing children's eating behaviours. Nutrients 10(6):706-723. https://doi. org/10.3390/nu10060706

UNICEF (2018). Nutrition Country Profile. Thailand. Global Nutrition Report. https:// globalnutritionreport.org/resources / nutritionprofiles/asia/south-eastern-asia/thailand/

Wali N, Agho KE \& Renzaho AMN (2020). Factors associated with stunting among children under 5 years in five South Asian Countries (2014-2018): Analysis of Demographic Health Surveys. Nutrients 12(12):3875-3902. https:// doi.org/ 10.3390/nu12123875.
WHO (2008). WHO child growth standards: Training course on child growth assessment. World Health Organization, Geneva. https://www. who.int/childgrowth/training/module_b_ measuring_growth.pdf

WHO (2010). Country Profile Indicators. Interpretation Guide. Nutrition Landscape Information System (NLIS). https://www.who. int/nutrition/nlis_interpretation_guide.pdf

WHO (2020a). Fact sheets on Malnutrition. Malnutrition. https://www.who.int/newsroom/fact-sheets/detail/malnutrition

WHO (2020b). WHO child growth standards: Length/height-for-age, weight-for-age, weightfor-length, weight -for-height and body mass index-for-age: Methods and development. World Health Organization. https://apps.who.int/ iris / handle/10665/43413

WHO (2021). Joint child malnutrition estimates. The Global Health Observatory. https://www.who. int/data/maternal-newborn-child-adolescent/ gama/activities-of-gama

Yakubu I, Akaateba MA \& Akanbang BAA (2014). A study of housing conditions and characteristics in the Tamale Metropolitan Area, Ghana. Habitat Int 44:394-402. https:/ / doi.org/10.1016/j.habitatint.2014.08.003 